\title{
Evaluación inmunológica durante el tratamiento de un caso de lepra dimorfa lepromatosa
}

\author{
Blanca María Morfín-Maciel, ${ }^{1}$ María del Carmen Jiménez Martínez ${ }^{2}$
}

\begin{abstract}
Background: Leprosy is a chronic granulomatous infection that affects skin and peripheral nerves. Its prevalence has declined, but is still observed mainly in poor rural areas.

Case report: A male city dweller with photophobia and chronic dermatosis in the face: nodular and erythematous lesions, pustules, keratitis and entropion, partial eyebrows loss, and edema on eyelids, chin, and nose bridge. The rest of the body had no lesion or lymphadenopathy. Biopsy revealed Langhans giant cell proliferation in the superficial dermis without epidermal atrophy. BAAR staining for detection were positive, no Virschow cells were observed, and Fite-Franco staining (leprosy-specific) was negative. Cutaneous tuberculosis was diagnosed. Rifampicin/ isoniazid/pyrazinamide and dialysate leukocyte extract were prescribed. A month later, the swelling had decreased significantly. Polymerase chain reaction (PCR) test was positive for Mycobacterium leprae. Flow cytometry showed CD4 count normalization. Long-term treatment with rifampicin, clofazimine, and dapsone was established.

Conclusions: The host's immune response determines the clinical features of the disease: if response is bad there will be vacuolated macrophages filled with bacilli (lepromatous leprosy). Clinical and histopathological findings help typing.
\end{abstract}

Keywords: Leprosy; Antituberculosis drugs; Dialyzed extract of leukocytes; Immunomodulation

Este artículo debe citarse como: Morfín-Maciel BM, Jiménez Martínez MC. Evaluación inmunológica durante el tratamiento de un caso de lepra dimorfa lepromatosa. Rev Alergia Mex. 2016;63(4):413-419

${ }^{1}$ Hospital San Angel Inn Chapultepec. Ciudad de México, México 2Universidad Nacional Autónoma de México, Ciudad Universitaria, Facultad de Medicina, Departamento de Bioquímica. Ciudad de México, México
Correspondencia: Blanca María Morfín-Maciel

blancamorfin@hotmail.com

Recibido: 2016-02-22

Aceptado: 2016-06-30 


\section{Resumen}

Antecedentes: La lepra es una infección granulomatosa crónica que afecta piel y nervios periféricos. Aunque su prevalencia ha disminuido, se sigue observando principalmente en el medio rural pobre.

Caso clínico: Hombre residente de una ciudad, con fotofobia y dermatosis crónica en la cara: lesiones nodulares y eritematosas, pústulas, queratitis y entropión, pérdida parcial de las cejas y edema de párpados, barbilla y puente nasal. El resto del cuerpo sin lesiones ni adenomegalias. La biopsia reveló proliferación de células gigantes de Langhans en la dermis superficial, sin atrofia epidérmica. Las tinciones para búsqueda de BAAR fueron positivas. No se observaron células de Virschow y la tinción de Fite-Franco (específica de lepra) fue negativa. Se diagnosticó tuberculosis cutánea. Se prescribió rifampicina-isoniazida-pirazinamida y extracto dializado de leucocitos. Un mes después, la inflamación había disminuido de forma importante. La reacción en cadena de la polimerasa fue positiva para Mycobacterium leprae. Con la citometría de flujo de seguimiento se observó normalización de la cuenta de CD4. Se estableció tratamiento a largo plazo con rifampicina, clofazimina y dapsona.

Conclusiones: La respuesta inmune del huésped determina las características clínicas de la enfermedad: si la respuesta es mala habrá macrófagos vacuolados llenos de bacilos (lepromatosa). Los hallazgos clínicos e histopatológicos ayudan a la tipificación.

Palabras clave: Lepra; Antifímicos; Extractos dializados de leucocitos; Inmunomodulación

\author{
Abreviaturas y siglas \\ BAAR bacilo ácido alcohol resistente \\ EDL, extracto dializado de leucocitos \\ GLP-1, glucolípido fenólico 1 \\ IL, interleucina \\ LT, lepra tuberculoide
}

\author{
LL, lepra lepromatosa \\ MB, multibacilar \\ NK, natural killer \\ $\mathrm{PB}$, paucibacilar \\ $\mathrm{PCR}$, reacción en cadena de la polimerasa \\ TNF- $\alpha$, factor de necrosis tumoral alfa
}

\section{Antecedentes}

La lepra es una infección granulomatosa crónica que afecta piel y nervios periféricos. El agente causal, Mycobacterium leprae es un bacilo ácido alcohol resistente (BAAR). ${ }^{1,2}$ Aun cuando se trata de una enfermedad conocida desde la antigüedad, los componentes celulares que determinan su capacidad patógena y supervivencia en el huésped casi no se conocen. ${ }^{3} \mathrm{Si}$ bien su prevalencia ha disminuido en el último decenio, aún es importante, principalmente en el medio rural pobre. Se presenta en todos los grupos de edad; hasta $20 \%$ de los individuos que la padecen son menores de 10 años. La relación según el sexo es de 2:1 hombre:mujer. ${ }^{2}$

La respuesta inmune del huésped determina las características clínicas de la lepra: con respuesta Th1 adecuada, la lesión será granulomatosa y los bacilos escasos (tuberculoide): si la respuesta es mala habrá macrófagos vacuolados llenos de bacilos (lepromatosa). Entre estos extremos existen grados intermedios de lepra:

- Indeterminada.

- Lepromatosa.

- Dimorfa lepromatosa.

- Dimorfa tuberculoide.

- Tuberculoide.

Los pacientes se mueven a lo largo de ese espectro clínico como resultado de la evolución de la enfermedad o de las intervenciones terapéuticas. ${ }^{4}$

En México predomina la lepra lepromatosa (LL) mientras que en Asia, la tuberculoide (LT). En 20\% de los individuos se inicia como lepra indeterminada, con máculas eritematosas o hipocrómicas, anestésicas, que remiten o se transforman en otro tipo de lepra. ${ }^{2}$ 
La LL comienza en piel y origina cambios neurales. Las máculas eritematosas o hipocrómicas, generalizadas y simétricas, evolucionan a lesiones nodulares infiltrativas que confluyen en la frente y párpados, dando la característica facies leonina. La forma difusa infiltra la piel sin nódulos. ${ }^{2,4}$ Por su parte, la LT origina lesiones solitarias, escasas y asimétricas, máculas hipopigmentadas, anestésicas, con pérdida del pelo y ausencia de sudoración, con el borde elevado y tendencia a la curación central. La lepra dimorfa muestra todo el espectro entre las lesiones polares. ${ }^{2,4}$

La transmisión persona-persona (por piel, saliva y secreciones nasales) se ha demostrado en 50\% de los casos y es menor en LT, pero también puede ocurrir por tatuajes o fómites (el factor de virulencia GLP-1 permanece en los objetos). El periodo de contagio es de 3 a 5 años (con un rango de 6 meses a 10 años), lo cual dificulta saber dónde y cuándo se contrajo la enfermedad. Entre los reservorios están el armadillo, los primates, así como insectos hematófagos. ${ }^{1,2}$

De acuerdo con la Organización Mundial de la Salud, el diagnóstico es clínico y se realiza con uno de los dos siguientes puntos:

- Lesiones cutáneas sugestivas de lepra con pérdida de la sensibilidad, con o sin engrosamiento de los nervios.

- Frotis de piel positivo al bacilo. Si el frotis es negativo se considerará paucibacilar (PB), mientras que si es positivo se considerará multibaci$\operatorname{lar}(\mathrm{MB})$.

Para el tratamiento de los casos MB se aconseja la administración de rifampicina-dapsona-clofazimina durante dos años; mientras que para los casos PB se recomienda rifampicina-dapsona. El seguimiento será clínico o idealmente por reacción en cadena de la polimerasa (PCR) para determinar la curación. ${ }^{1}$

\section{Caso clínico}

Hombre de 47 años, conductor de vehículos automotores, residente en la Ciudad de México, sin antecedentes patológicos de importancia. Acudió a consulta por dermatosis crónica y fotofobia de dos meses de evolución, con afección de la cara y cejas, por lo que había recibido antihistamínicos, tacroli- mus y esteroides tópicos, sin mejoría. Los análisis de laboratorio indicaban Combe y prueba de Mantoux negativos.

El paciente presentaba picazón difusa en la cara y caída de las cejas, así como lesiones de aspecto nodular y eritematoso en zona frontal y malar, que confluían en placas induradas convexas, de bordes mal definidos en el entrecejo, con discreta hipoestesia de la zona, pequeñas pústulas en la barbilla y zona nasogeniana, eritema y edema discretos en el borde del labio superior, queratitis y entropión, pérdida parcial de las porciones laterales de las cejas y edema importante de párpados, barbilla y del puente nasal, lo que confería facies leonina al paciente (Figura 1). La fundoscopia fue normal. Los pabellones auriculares y la piel del resto del cuerpo no mostraban lesiones. No se palparon adenomegalias. El tabique nasal y la faringe se encontraron normales. No se palparon induraciones o engrosamientos en los nervios de los antebrazos. No había afección testicular.

La biopsia reveló proliferación de células gigantes de Langhans (fusión de macrófagos activados con acumulación de núcleos en forma de herradura en la periferia), distribuidas en la dermis superficial y alrededor de los anexos, con necrosis caseosa, des-

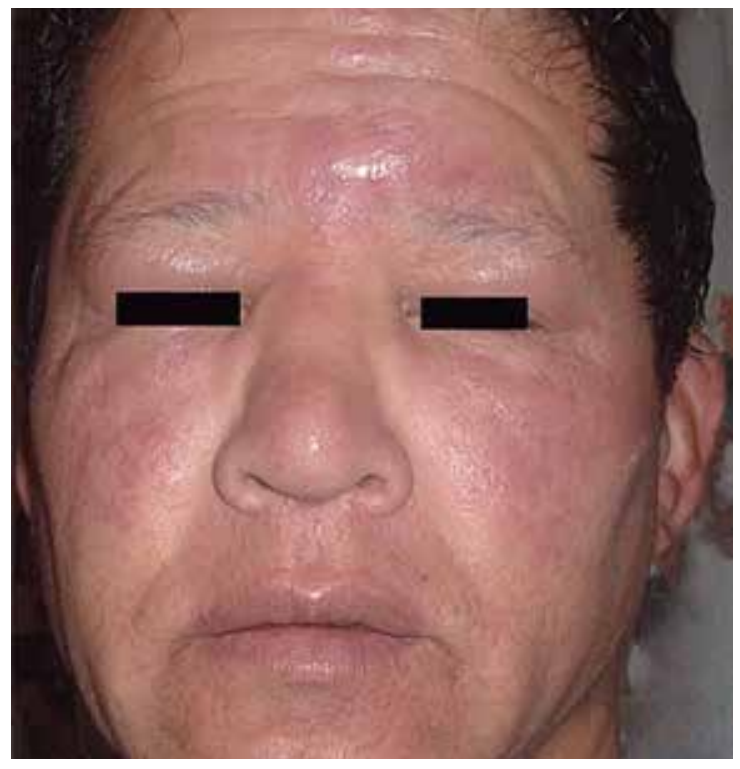

Figura 1. Aspecto de facies leonina en paciente con lepra dimorfa lepromatosa al iniciar tratamiento. (Con autorización del paciente). 
trucción del nervio central e infiltrado inflamatorio de células plasmáticas, linfocitos y eosinófilos. Las células epitelioides estaban rodeadas de linfocitos CD4. No se observó atrofia epidérmica. La búsqueda de BAAR (con tinción de Ziehl-Neelsen) fue positiva en la zona de necrosis perianexial, donde se encontraron escasos bacilos intracelulares. No se observaron células de Virschow. La tinción de FiteFranco (específica para identificación de Mycobacterium leprae) fue negativa, por lo que se estableció diagnóstico de tuberculosis cutánea.

Las pruebas de función hepática fueron normales: bilirrubina total de $0.8 \mathrm{mg} / \mathrm{dL}$, alanina aminotransferasa de $22 \mathrm{UI} / \mathrm{L}$, aspartato aminotransferasa de $20 \mathrm{UI} / \mathrm{L}$ y gamma glutamil transpeptidasa de $28 \mathrm{UI} / \mathrm{L}$. La citometría de flujo al momento del diagnóstico indicó disminución leve de linfocitos CD4, con un radio CD4/CD8 de 0.57 (Cuadro 1). La radiografía de tórax fue normal.

Se inició manejo con una combinación de 600 $\mathrm{mg}$ de rifampicina $(7.3 \mathrm{mg} / \mathrm{kg} / \mathrm{día}), 300 \mathrm{mg}$ de isoniazida $(3.7 \mathrm{mg} / \mathrm{kg} / \mathrm{día})$ y $1600 \mathrm{mg}$ de pirazinamida (Rifater ${ }^{\circledR}$, Sanofi-Aventis, México, cuatro tabletas diarias en una dosis) y extracto dializado de leucocitos (EDL) como adyuvante, a dosis de 1 unidad (2 mg) diaria por 5 días y posteriormente una unidad semanal por 7 semanas más.

Un mes después se observó mejoría notoria de las lesiones inflamatorias, con disminución de las placas nodulares eritematosas en entrecejo y zonas malares, del edema palpebral y del puente nasal, si bien persistía la hipoestesia en la frente (Figura 2); la conjuntiva ya no lucía hiperémica, la fotofobia había disminuido y el entropión había desaparecido. Las pruebas de función hepática se encontraron normales (bilirrubina total de $1.2 \mathrm{mg} / \mathrm{dL}$; alanina aminotransferasa de 36 $\mathrm{UI} / \mathrm{L}$; aspartato aminotransferasa de $32 \mathrm{UI} / \mathrm{L}$ y gamma glutamil transpeptidasa de $40 \mathrm{UI} / \mathrm{L}$ ); la PCR fue positiva para Mycobacterium leprae. La citometría de flujo de seguimiento indicó normalización de la cuenta de $\mathrm{CD} 4$, con un radio $\mathrm{CD} 4 / \mathrm{CD} 8$ de 1.5 (Cuadro 1). No se realizó intradermorreacción con lepromina.

Antes de completar el esquema de dos meses, el paciente fue enviado a un centro de referencia especializado en dermatosis para su tratamiento a largo plazo con rifampicina, clofazimina y dapsona.

\begin{tabular}{|c|c|c|c|}
\hline \multirow[b]{2}{*}{ Fenotipo celular } & \multicolumn{3}{|c|}{ Valores } \\
\hline & Iniciales & Al mes & Rango de referencia \\
\hline Linfocitos absolutos (cel/ $\mu \mathrm{L})$ & 2230 & 3580 & $825-3875$ \\
\hline \multicolumn{4}{|l|}{ Células B totales CD19 } \\
\hline Conteo absoluto (cel/ $/ \mu \mathrm{L})$ & 558 & 429 & $75-580$ \\
\hline$\%$ CD19 & 25 & 12 & $5-20$ \\
\hline \multicolumn{4}{|l|}{ Células $\mathrm{T}$ totales CD3 } \\
\hline Conteo absoluto (cel/ $/ \mu \mathrm{L})$ & 1538 & 2685 & $805-3530$ \\
\hline$\%$ CD3 \% & 69 & 75 & $58-85$ \\
\hline \multicolumn{4}{|l|}{ Subtipos linfocitos T CD4 } \\
\hline Conteo absoluto (cel/ $/ \mu \mathrm{L})$ & 557 & 1611 & $518-2620$ \\
\hline$\%$ CD4 & 25 & 45 & $30-60$ \\
\hline \multicolumn{4}{|l|}{ CD8 } \\
\hline Conteo absoluto (cel/ $/ \mu \mathrm{L})$ & 981 & 1074 & $200-1410$ \\
\hline \% CD8 & 44 & 30 & $15-38$ \\
\hline \multicolumn{4}{|l|}{ Células NK } \\
\hline Conteo absoluto CD3-CD16+CD56 (cel/ $/ \mu \mathrm{L})$ & 133 & 465 & $55-555$ \\
\hline \% CD3-CD16+CD56+ & 6 & 13 & $2-16$ \\
\hline Radio CD4/CD8 & 0.57 & 1.5 & $0.86-5$ \\
\hline
\end{tabular}




\section{Discusión}

La lepra es una enfermedad infecciosa por Mycobacterium leprae, cuyo amplio espectro clínico correlaciona con los perfiles inmunológicos Th1/Th2. En la LL predomina el perfil Th2 (IL-4, IL-5, IL-10 e IL-13) y la inmunidad celular (Th1) está impedida, por lo que los linfocitos CD8 y las micobacterias son abundantes en las lesiones cutáneas. ${ }^{5} \mathrm{El}$ factor de virulencia glucolípido fenólico 1 (GLP-1) se une a C3, y junto con citocinas Th2 bloquea la fagocitosis y la acción bactericida de los macrófagos. ${ }^{3,6}$ En la LL, el defecto en la inmunidad celular es muy específico y los enfermos no tienen mayor morbilidad por infecciones virales, hongos o protozoarios, ni mayor riesgo de neoplasias. ${ }^{6}$ En la LT, la respuesta Th1 (IL-12, INF $\gamma$ ) es adecuada, por lo que hay pocos organismos y los CD4 predominan en las lesiones (Figura 3). 5,6

El eritema indurado caracteriza las lesiones cutáneas por hipersensibilidad tardía. Con la biopsia de piel se confirma el diagnóstico y se cataloga el tipo de lepra. La inflamación granulomatosa en LT dada por IL-12 denota reacción inflamatoria crónica,

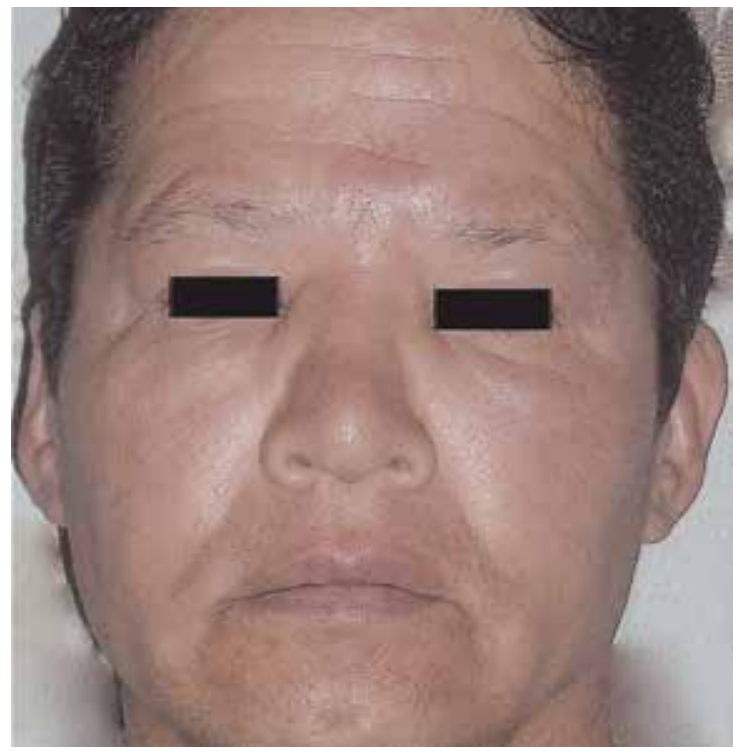

Figura 2. Aspecto facial del paciente con lepra dimorfa lepromatosa después de un mes de tratamiento con antifímicos y extracto dializable de leucocitos. (Con autorización del paciente)

\begin{tabular}{|c|c|c|c|c|}
\hline Lepra tuberculoide & \multirow{17}{*}{ 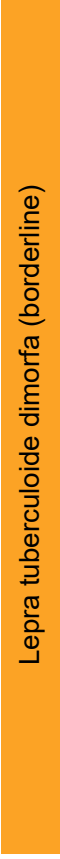 } & \multirow{17}{*}{ 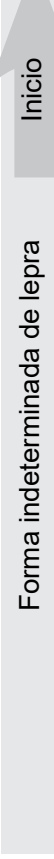 } & \multirow{17}{*}{ 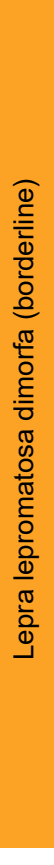 } & Lepra lepromatosa \\
\hline HLA DR2, HLA DR3 & & & & HLA DQ1 \\
\hline Respuesta celular lenta & & & & Respuesta humoral (IgG, IgM) \\
\hline Predominio Th1 & & & & Predominio Th2 \\
\hline Resistencia a infección & & & & Anergia \\
\hline Buena respuesta adaptativa & & & & Mala respuesta adaptativa \\
\hline Paucibacilar & & & & Multibacilar \\
\hline Localizada & & & & Diseminada/difusa \\
\hline Granuloma epitelioide & & & & Granuloma vacuolado \\
\hline Respuesta NK adecuada & & & & Mala respuesta NK \\
\hline 个 IL-2, IL-7, IL-12, IL-15, IL-18, IL-1 $\beta$ & & & & 个 IL-4, IL-5, IL-10, IL-13 \\
\hline 个 INF-Y & & & & $\uparrow \mathrm{TGF}-\beta 1$ \\
\hline $\boldsymbol{\varphi}$ TNF- $\alpha$ & & & & 个个 TNF-a (más en reacción tipo 2) \\
\hline CD4 en lesiones & & & & CD8 en lesiones \\
\hline TLR1, TLR2++++ & & & & TLR1, TLR2 \pm \\
\hline & & & & 个 Linfocitos $T$ reguladores \\
\hline & & & & Supresión de linfocitos T por GLP-1 \\
\hline
\end{tabular}

Figura 3. Respuesta inmune en la polarización de la lepra y estados intermedios. Tomado de referencia 8. 
por persistencia del patógeno, hay acumulación focal de los macrófagos activados, que confluyen formando células epitelioides rodeadas de células mononucleares y células plasmáticas, que se funden formando células gigantes de Langerhans que contienen varios núcleos pequeños en la periferia. ${ }^{6}$ En la LL, los macrófagos están repletos de bacilos, pero son incapaces de digerirlos. Por su citoplasma vacuolado, lucen espumosos (células de Virschow). ${ }^{7}$ El GLP-1 y otros lípidos recubren al Mycobacterium leprae, impidiendo su destrucción oxidativa por radicales hidroxilo y aniones superóxido, lo que favorece el escape a la vigilancia inmunológica y origina una respuesta inflamatoria muy lenta. ${ }^{3}$ Además, Mycobacterium leprae induce apoptosis de macrófagos derivados de monocitos en una forma dosis dependiente, a través de citocinas proapoptóticas como el factor de necrosis tumoral alfa (TNF- $\alpha$ ). ${ }^{7}$

Tanto el predominio Th1 en LT como el predominio Th2 en LL son estadios de la enfermedad. La polarización clínica e inmunológica entre los dos extremos origina los diversos cuadros (Figura 3), de ahí que los pacientes transiten a lo largo de este espectro como parte de la historia natural de la enfermedad o en respuesta a las intervenciones terapéuticas. ${ }^{8}$

El paciente descrito fue considerado dimorfo porque las características clínicas sugerían LL (facies leonina), pero la evidencia histológica mostró LT (granulomas con escasos bacilos, células de Langhans, y destrucción del nervio). Aunque la imagen histológica fue confundida inicialmente con tuberculosis cutánea, la necrosis caseosa intraneural es típica de la lepra. ${ }^{4}$ La confusión en el diagnóstico inicial de la lepra con tuberculosis es frecuente, no solo por la semejanza clínica de las lesiones granulomatosas, sino porque la tinción modificada de Ziehl-Neelsen puede también colorear a Mycobacterium leprae.$^{4}$ En el paciente descrito, el diagnóstico fue esclarecido con PCR, altamente sensible y específica (99\% certeza), que resultó positiva para el bacilo de Hansen. ${ }^{9}$

Para el tratamiento de la lepra, la Organización Mundial de la Salud recomienda administrar 2 a 3 fármacos por 3 a 5 años, usando como base rifampicina, clofazimina y dapsona. ${ }^{1}$ En el paciente referido, dado el reporte inicial de la biopsia (tuberculosis cutánea), se utilizó una combinación de rifampicina, isoniazida y pirazinamida. La pirazinamida actúa contra microorganismos intracelulares en el medio ácido de los macrófagos. La rifampicina y la isoniazida son bactericidas intracelulares. La rifampicina inhibe la actividad de la ARN polimerasa bacteriana de Mycobacterium tuberculosis y Mycobacterium leprae, por ello, el tratamiento inicial logró un efecto benéfico.

La rifampicina es el fármaco que ataca con mayor rapidez al bacilo de Hansen; los bacilos se vuelven casi indetectables después de cinco días de una dosis única de $1500 \mathrm{mg}$. La dosis recomendada es de $600 \mathrm{mg} /$ día y la resistencia a este fármaco es rara. ${ }^{2}$ La respuesta a la terapia es muy lenta: los nódulos y placas de la LL se aplanan visiblemente después de tres meses de recibir tratamiento. La respuesta en la forma dimorfa y en LT es más lenta. ${ }^{10}$

Es posible que la rápida respuesta terapéutica en el paciente se debiera a la combinación de antifímicos $y$ al efecto adyuvante del EDL. En un modelo experimental murino de lepra, la mejoría clínica de los animales infectados y tratados con EDL se evidenció con la reducción en la extensión y número de bacilos en los granulomas, así como en el desarrollo de tejido de granulación, indicativo de mejoría clínica, la cual fue mayor en los ratones que recibieron EDL combinado con bactericidas. ${ }^{10,11}$ En el paciente descrito, al igual que en el modelo murino, se redujo el tamaño de los nódulos y la sintomatología clínica. Además, se registraron cambios en la citometría que sugieren reforzamiento del perfil Th1: se incrementaron los linfocitos CD4 y las células NK y se redujeron levemente las CD19. La relación CD4/CD8 se incrementó a 1.5.

\section{Conclusiones}

Se informó de un paciente con lepra dimorfa lepromatosa y deficiencia leve de $\mathrm{CD} 4+$, diagnosticada inicialmente como tuberculosis cutánea, quien respondió rápidamente a tratamiento antifímico y EDL, el cual ha sido utilizado como adyuvante en diversas enfermedades. ${ }^{12-15}$ En este paciente se utilizó Transferon ${ }^{\circledR}$ (Instituto Politécnico Nacional, México), mezcla heterogénea de péptidos de bajo peso molecular $(<10 \mathrm{kDa})$ liberados por la ruptura de leucocitos de sangre periférica de donadores sanos y cuyas acciones inmunológicas demostradas son la inducción in vitro de INF- $\gamma$ en una línea celular de linfocitos $T,{ }^{16}$ en modelos animales in vivo ${ }^{17} \mathrm{y}$ en pacientes con inmunidad Th1 funcionalmente disminuida o alterada. ${ }^{14,15}$ La producción de citocinas Th1 pudo reestablecer la inmunidad celular y la función bactericida de los macrófagos, como fue reportado en el modelo murino de lepra anérgica. 


\section{Referencias}

1. World Health Organization [sitio web]. Programmes. Leprosy elimination. [Citado 2015 Nov 17]. Disponible en: http://www.who.int/lep/leprosy/en/

2. Eichelmann K, González GSE, Salas-Alanis JC, Ocampo-Candian J. Lepra: puesta al día. Definición, patogénesis, clasificación, diagnóstico y tratamiento. Actas Dermo-Sifiliogr. 2013;104(7):554-563. doi: 10.1016/j.ad.2012.03.003

3. Guenin-Macé L, Siméone R, Demangel C. Lipids of pathogenic Mycobacteria: Contributions to virulence and host immune supression. Transbound Emerg Dis. 2009;56(6-7):255-268. doi: 10.1111/j.18651682.2009.01072.x

4. Moreno A, Servitje O. Lepra. En: Herrera E, Moreno A, Requena L, Rodríguez-Peralto JL. Dermatopatología. Correlación clínico-patológica. Madrid, España. Menarini; 2007. p. 307-311.

5. Lucey DR, Clerici M, Shearer GM. Type 1 and type 2 cytokine dysregulation in human infectious, neoplastic, and inflammatory diseases. Clin Microbiol Rev. 1996;9(4):532-562.

6. Lima BS, Pereira GMB, Rumjanek FD, Gomes HM, Duppre N, Sampaio EP, et al. Immunological cytokine correlates of protective immunity and pathogenesis in leprosy. Scand J Immunol. 2000;51(4):419-428.

7. Hernández MO, Neves I, Sales JS, Carvalho DS, Sarno EN. Induction of apoptosis in monocytes by M. leprae in vitro: A possible role for tumor necrosis factor-a. Immunology. 2003;109(1):156-164.

8. Rada E, Aranzazu N, Convit J. Respuesta inmunitaria de la enfermedad de Hansen. Revisión. Invest Clin. 2009;50(4):513-527.

9. Nóbrega MA, Talhari C, Ozório MM, Talhari S. PCR-based techniques for leprosy diagnosis: From the laboratory to the clinic. PLoS Negl Trop Dis. 2014;8(4):e2655. doi: 10.1371/journal.pntd.0002655

10. Gelber RH. Lepra. En: Longo DL, Fauci AS, Kasper DL, Hauser SL, Jameson JL, Loscalzo J, editores. Harrison. Principios de medicina interna. Vol. 1. Décima novena edición. NY, USA; McGraw-Hill; 2012. p. $1203-1212$.

11. Juárez-Ortega M, Hernández VG, Arce-Paredes $P$, Villanueva EB, Aguilar-Santelises M, Rojas-Espinosa O. Induction and treatment of anergy in murine leprosy. Int J Exp Pathol. 2015;96(1):31-41.

12. Kirkpatrick, $\mathrm{CH}$, Smith TK. The nature of transfer factor and its clinical efficacy in the management of cutaneous disorders. J Investig Dermatol 1976;67(3):425-430.

13. Viza D, Fudenberg HH, Palareti A, Ablashi D, De Vinci C, Pizza G. Transfer factor: An overlooked potential for the prevention and treatment of infectious diseases. Folia Biol (Praha). 2013;59(2):53-67.

14. Estrada-Parra S, Nagaya A, Serrano E, Rodríguez O, Santamaria V, Ondarza R, et al. Comparative study of transfer factor and acyclovir in the treatment of herpes zoster. Int $\mathrm{J}$ Immunopharmacol. 1998;20(10):521-535.

15. Luna-Baca GA, Linares M, Santacruz-Valdés C, Aguilar-Velázquez G, Chávez R, Pérez-Tapia M, et al. Immunological study of patients with herpetic stromal keratitis treated with dialyzable leukocyte extracts. $13^{\text {th }}$ International Congress of Immunology-ICI. Proceedings Immunology. Río de Janeiro, 21-25 de agosto de 2007; p. 67-70

16. Medina-Rivero E, Merchand-Reyes G, Pavón L, Vázquez-Leyva S, Pérez-Sánchez G, Salinas-Jazmín N, et al. Batch-to-batch reproducibility of Transferon ${ }^{\text {TM }}$. J Pharm Biomed Anal. 2014;88:289-294. doi: 10.1016/j.jpba.2013.09.004

17. Salinas-Jazmín N, Estrada-Parra S, Becerril-García MA, Limón-Flores AY, Vázquez-Leyva S, MedinaRivero E, et al. Herpes murine model as a biological assay to test dialyzable leukocyte extracts activity. J Immunol Res. 2015; Article ID 146305. [9 pages] doi:10.1155/2015/146305 